\title{
Н. В. Гоголь и проблемы «философии хозяйства» (И. А. Гончаров, Л. Н. Толстой, С. Н. Булгаков)
}

\author{
СЕРГЕЙ ШУЛЬЦ \\ ул. Искусственная, д. 2/А, кв. 12, RU-344019 Ростов-на-Дону \\ E-mail: s_shulz@mail.ru
}

(Received: 3 April 2016; accepted: 23 June 2016)

\begin{abstract}
Gogol's art (first of all, his works Dead Souls and Selected Passages from the Correspondence with the Friends) is considered in the aspect of the problem of a "philosophy of an economy" formulated by S. Bulgakov. Gogol's views also are correlated with its development in the art of I. Goncharov (Oblomov) and L. Tolstoy (first of all, his late works).

Keywords: philosophy of an economy, N. Gogol, S. Bulgakov, I. Goncharov, L. Tolstoy
\end{abstract}

С. Н. Булгаков, особо тематизировавший в русской мысли идею «философии хозяйства» (Булг Аков 1993b), имел предшественников в лице «московского православия» (выражение Н. А. Бердяева) - о «домостроительстве» писали до него Амвросий Оптинский, Феофан Затворник и др. (БЕРдяев 1991: 175). Однако именно С. Н. Булгаков впервые поставил вопрос в широком философском и теологическом контексте. Хозяйство мыслитель понимает в самом общем плане возвращения потерянного Эдема (СЕменовА-ГАчеВА 1993: 131), возобновления человеческого «владычества над созданиями природы» (Бэкон 1972: 222), ${ }^{1}$ что сочетается у Булгакова с долей естественнонаучных подходов и отчасти экономическим материализмом, напоминающими о его марксистском прошлом.

Хозяйство у Булгакова отождествляется и с преображением, в том числе техническим, природы (самой природой), и вместе с тем с культурой как деятельностью по изменению мира:

...природа в своих основах есть уже nata [т. е. рожденная, созданная - С. Ш.], создана, однако она еще воссозидаема - есть natura, и, насколько воссоздание это совершается через культуру, можно сказать, что культура воссозидает натуру - обычное противопоставление натуры и культуры этим снимается (БулГАКОВ 1993a: 134).

В. В. Зеньковский, специально осмыслявший постановку проблемы хозяйствования у Гоголя, вписал вопрос в культурно-исторический контекст $\mathrm{XIX-XX} \mathrm{вв.,} \mathrm{пунктирно} \mathrm{наметив} \mathrm{связи} \mathrm{Гоголя} \mathrm{в} \mathrm{том} \mathrm{числе} \mathrm{с} \mathrm{С.} \mathrm{Н.} \mathrm{Булгако-}$ вым, Н. Ф. Федоровым (см. также Никитин 1989), Толстым и др. (ЗЕньковский

${ }^{1}$ Отрывки из этой работы публиковались по-русски еще во второй половине XVIII в. 
1997: 149-163). Нам представляется важным попытаться подробно рассмотреть заявленную в заглавии тему в философско-поэтологическом плане.

Гоголю оказывается близка мысль Булгакова о взаимосвязи и взаимопереходе живого и мертвого:

...ничего неживого вовсе и нет, и лишь тяжелый кошмар наложил на бытие это оцепенение, эту мертвую маску. Смерть есть в мире; да, все родящееся умирает, но есть ли эта смерть подлинная и окончательная смерть, а не новое лишь рождение или перерыв и отсрочка жизни? (БулгАков 1993а: 135).

В то же время слова Булгакова: «Творить жизнь невозможно и потому, что все бытие уже есть жизнь» - с точки зрения Гоголя слишком категоричны, так как творчество для Гоголя по-романтически безгранично. Если для Булгакова космогонический процесс (становление миропорядка; социальный порядок выступает частью космического - см. ЭлиАдЕ 2009: 116) уже завершен, то для Гоголя это неочевидно.

Булгаков также говорит о творчестве, искусстве в широком значении, но понимая их несколько условно: «Содержанием хозяйственной деятельности человека является не творчество жизни, но ее защита, воссоздание живого и натиск на омертвелое» (БулгАКов 1993а: 136). Иначе говоря, согласно Булгакову, человек ограничен наличным. Вместе с тем Булгаков почти в русле Гоголя сравнивает хозяйственную деятельность с искусством: земному обустройству «иерархически и космологически предшествует иное хозяйство, иной труд, свободный, бескорыстный, любовный, в котором хозяйство сливается с художественным творчеством»; «искусство есть цель и предел хозяйства, хозяйство должно возвратиться к своему первообразу, превратиться в искусство» (БулГАКОВ 1993а: 140).

Сопоставление художника и хозяйственника - вполне в духе Гоголя, мечтавшего своим искусством преобразить мир. Вместе с тем идеальный хозяйственник, как он предстает во втором томе Mepmвых душ и в Bыбранных местах из переписки с друзьями - для Гоголя скорее прагматик и рационалистически мыслящий «богослов». Сам Гоголь как художник предстает в одном из своих воплощений таким «прагматиком», но не искомые им прагматики - художниками.

Гоголь в Mepmвых душах и в отдельных главах Bыбранных мест попытался создать целую «теологию» хозяйства. С одной стороны, земной мир для него - лишь преддверие к жизни вечной. А с другой, Гоголь пытается найти пути обустройства человека в посюсторонности. Идеалом подобного обустройства для Гоголя было помещичье имение - даже Бога он называл «Небесным Помещиком». Это связано не столько с гоголевским «консерватизмом», сколько с тем, что он в данном случае мыслил в высоком значении «абстрактно» и хотел уйти от рассуждений о неизвестном, от утопизма. Это напоминает отчасти принципы построения Платона, не избегавшего в своем идеальном государстве рабства. 
Но гоголевская консервативная идиллия сама стала утопией. В ней парадоксально сочетается стремление удержать старину и вместе с тем взрастить в последней семена «нового».

В мире Вечеров на хуторе близ Диканьки снедь производилась словно сама собой - галушки сами прыгали Пацюку в рот. Пышная природа словно бы сама по себе давала обильный урожай, хозяйство было вписано в мир роскошной природы, которой не надо было «овладевать» и которую не надо было «покорять». После падения мира «старосветских помещиков», после предфутуристической урбанистики Петербургских повестей и комедий Гоголь в 1840-е гг. вновь обращается к мифологеме земли. Теперь оказывается, что ее нужно должным образом обрабатывать.

После первого тома Гоголь в ряде заметок пытался оправдать тех или иных своих помещиков - например, Коробочку или Собакевича, у которых мужики, как оказывается, живут почти в довольстве. Именно забота о мужиках объявлена главным делом русского помещика во втором томе, а также в Выбранных местах:

Припомни отношения прежних помещиков-хозяинов к своим мужикам: будь патриархом, сам начинателем всего и передовым во всех делах. Заведи, чтобы при начале всякого общего дела, как-то: посева, покосов и уборки хлеба - был пир на всю деревню, чтобы в эти дни был общий стол для всех мужиков на твоем дворе, как бы в день самого Светлого Воскресенья, и обедал бы ты сам вместе с ними, и вместе с ними вышел бы на работу, и в работе был бы передовым, подстрекая всех работать молодцами, похваливая тут же удальца и укоряя ленивца. [...] В комнате не засиживайся, но появляйся почаще на крестьянских работах (Гоголь 6: 112).

В описании подобной трудовой идиллии явственно воздействие не только Ветхого завета, но и посвященных сельской жизни Вольмаров страниц Юлии, или Новой Элоизы Руссо. В поместье барона крестьяне и господа живут в некоем идиллическом единении. Впоследствии прямой руссоизм обнаружится в описании деревенского бытия Левина в Анне Карениной - через стремление Левина слиться с «общей жизнью» крестьян. Но и в страстях Анны, бросающей вызов свету, - все тот же «руссоизм», хотя, конечно, вне хозяйственной жилки.

Одна из сквозных идей второго тома - делать все в мысли не столько о людях, сколько о Боге.

Крайне примечателен один из диалогов благородного откупщика Муразова с Хлобуевым:

Муразов глядел пристально ему в лицо, но бедный Хлобуев ничего не мог отвечать. Муразову стало его жалко.

- Послушайте, Семен Семенович, но ведь вы же молитесь, ходите в церковь, не пропускаете... ни утрени, ни вечерни. Вам хоть и не хочется рано вставать, но ведь вы встаете же и идете, - идете в четыре часа утра, когда никто не подымается. 
- Это другое дело, Афанасий Васильевич. Я знаю, что это я делаю не для человека, но для Того, Кто приказал нам быть всем на свете. Что ж делать? Я верю, что Он милостив ко мне, что как я ни мерзок, ни гадок, но Он меня может простить и принять, тогда как люди оттолкнут ногою и наилучший из друзей продаст меня, да еще скажет потом, что он продал из благой цели (ГоГоль 5: 461).

Муразов неожиданно подхватывает слова Хлобуева:

- Так послужите же Тому, Который так милостив. Ему так же угоден труд, как и молитва. Возьмите какое ни есть занятие, но возьмите как бы вы делали для Него, а не для людей. Ну, просто хоть воду толките в ступе, но помышляйте только, что вы делаете для Него. Уж этим будет выгода, что дурного не останется времени - для проигрыша в карты, для пирушки с объедалами, для светской жизни (ГОГОль 5: 461).

Идея служения Богу, а не людям подразумевает служение тем самым также и людям, но перенос акцентов принципиален. Так вскрывается «теология» хозяйства по-гоголевски: сотворчество Творца и отдельного индивида. В «Наброске к окончанию Meртвых душ» Гоголь напишет:

Зачем же ты не вспомнил обо Мне, что Я на тебя гляжу, что Я твой? Зачем же ты от людей, а не от Меня ожидал награды и вниманья, и поощренья? [Зачем не шел ты до конца, закрывши глаза на людей и смотря только...] Какое бы тогда было тебе дело обра<щать внимание?>, как издержит твои деньги земной помещик, когда у тебя Небесный Помещик? Кто знает, чем бы кончилось, если бы <ты> до конца дошел, не устрашившись? Ты бы удивил величием характ<ера>, ты бы наконец взял верх и заставил изумиться; ты бы оставил имя, как вечный памятник доблести, и роняли бы ручьи слез, потоки слезные о тебе и как вихорь ты бы развевал в сердцах пламень добра.

Потупил голову, устыдившись, управитель, и не знал, куды ему деться.

И много вслед за ним чиновников и благородных, прекрасных людей, начавших служить и потом бросивших поприще, печально понурили головы» (Гоголь 5: 495).

«Закрыть глаза на людей» и смотреть только на Бога означает акцент на внутренней субстанции человека (совесть, душа, дух) и потустороннем. Так земное обустройство становится актом общей, продолжающейся в сотворчестве Бога и отдельного человека космогонии. Этот процесс подразумевает внутреннюю трансформацию каждого человека во имя внешних изменений, которые оказываются преображениями уже существующей действительности - т. е. ничего не «меняется», но лишь возвращается к некоей исконности, к тому, что уже задано (в замысле и т. п.) и тем самым уже есть.

В соответствии с этим Гоголь подчеркивал ведущую роль слова, а не дела:

...кто бы крикнул душе пробуждающим криком это бодрящее слово: вперед, которого жаждет повсюду, на всех ступенях стоящий, всех сословий, и званий, и помыслов, русский человек? 
Где же тот, кто бы на родном языке русской души нашей умел бы нам сказать это всемогущее слово вперед!, кто, зная все силы, и свойства, и всю глубину нашей природы, одним чародейным мановеньем мог бы устремить нас на высокую жизнь? [выделено Гоголем] (Гоголь 5: 385).

Вроде бы речь идет и о деле («вперед»), но оно предстает в виде словесного магического побуждения («одним чародейным мановеньем»), почти приравниваемого к достижению результата. Кроме того, слово «вперед» должно быть произнесено именно для «души» («кто бы крикнул душе»), т. е. для «внутреннего человека».

В одной из рецензий 1836 г. Гоголь обнаруживает в современной ему эпохе соединение теории и практики, причем под последней имеется в виду исторически понятое искусство:

В наш век почти общим сочувствием была признана необходимость воплощения всякой мысли практически. Она всегда должна торжествовать, как прекрасную эпоху, это начинающее $<$ ся> соединение теории с практикою, следуя великой, но простой истине, что дела более значат, нежели слова (Гоголь 7: 495).

«Дела» для Гоголя - само развивающее какую-либо философскую мысль искусство, что явствует из его дальнейшего изложения в цитированной рецензии.

Пассаж о «словах» и «делах» обнаруживает полемическую парафразу из Фауста Гете, провозгласившего в первой части трагедии, что «в начале было Дело» (ГетЕ 1976: 47). Слово уже и есть дело, отвечает Гете Гоголь. В этом отношении утопия Гоголя противопоставлена утопическому финалу второй части гетевского Фауста, где протагонист пытается вершить свои техницистские проекты в качестве элемента «дела». Финальный техницизм Фауста - «для людей», но он и против людей, поскольку разрушает блаженную идиллию Филемона и Бавкиды (ср. образы гоголевских «старосветских помещиков»). Это связано с фаустовским богоборчеством.

Гоголь после Вечеров с их также по-своему «естественным» хронотопом приходит в 1840-е гг. к выстраиванию идеи личности в ее отношениях с Богом как подателем самое «исконности», самое «естественности», долженствующих, однако, пройти через школу внутренней индивидуальной работы. Подобные построения далеки от «философии хозяйства» Булгакова, оставляющей «внутреннее» несколько в стороне и делающей ставку на внешние преобразования «внешнего» же. Вместе с тем софиология Булгакова, его идея «софийности» хозяйства, преображенного в задании, обращает также к замыслу о мире и человеке, тем самым, отчасти, к «внутреннему». Но, по вполне справедливому замечанию Н. А. Бердяева, «остается впечатление, что София подменяет Христа: самого Христа почти боятся» (БЕРдяев 1991: 178).

Во 2-м томе Тентетников объявлен «обладателем земного рая» (Гоголь 5: 381), впрочем, запущенного нерадивым хозяином. Тентетников, несмотря на предпринимаемые им попытки улучшений в своем имении, сближения 
с крестьянами, как был, так и остается принадлежащим «к семейству тех людей, которые на Руси не переводятся, которым прежде имена были: увальни, лежебоки, байбаки» (Гоголь 5: 374).

Идеальным помещиком призван был стать Костанжогло, в облике которого подчеркнуты архетипы «хозяина» и «царя» (ГольдЕНБЕРГ 2012: 66-75) и вместе с тем - нечто демоническое (сравнение с «колдуном»).

Тентетникова часто справедливо сравнивают с Обломовым как его «продолжением» (Анненский 1988b: 630). Основу для подобного сравнения Гончаров заложил в словах, прямо вводящих символику живого и мертвого:

Тогда еще он был молод, и если нельзя сказать, чтоб он был жив, то по крайней мере живее, чем теперь; еще он был полон разных стремлений, все чего-то надеялся, ждал многого и от судьбы и от самого себя; все готовился к поприщу, к роли (ГончАРОВ 1998: 55).

Гончаровым особо подчеркнуто, что апатия Обломова происходит не от болезни или случайности или тем более сибаритства и лени, а что она составляет основу совершающейся в нем внутренней работы в качестве «нормального состояния»:

Лежанье у Ильи Ильича не было ни необходимостью, как у больного или как у человека, который хочет спасть, ни случайностью, как у того, кто устал, ни наслаждением, как у лентяя: это было его нормальным состоянием (ГончАРов 1998: 5-6).

На эти глубокомысленные, исполненные философского пафоса слова, к сожалению, не всегда обращают внимание.

Мир Обломовки, каким он предстает в знаменитом сне протагониста, мир идиллии:

Вот природа, как ни одни из новых поэтов не понимает ее, - природа, лишенная тайны, ограниченная и прекрасная, какой представляли ее древние: декорация для идиллии феокритовских пастухов или, еще лучше, для счастья патриархальных помещиков (МЕРЕжкОвский 1991: 128).

Даже смерть в ней легка, как сон. В то же время насчет якобы лишенности природы тайны Мережковским сказано не совсем точно: Обломов как представитель своего рода нового «естественного человека», человека природы, обладает такой тайной, подобно самой природе.

Загадочность, амбивалентность образа Обломова подчеркнута фразой:

О способностях его, об его внутренней вулканической работе пылкой головы, гуманного сердца знал подробно и мог свидетельствовать Штольц, но Штольца почти никогда не было в Петербурге (ГончАРов 1998: 67).

Таким образом, таинственная сложность Обломова, заметная только Штольцу, должна быть явлена и остальным - как «ровный свет беспечности» 
и «мягкость, которая была господствующим и основным выражением... всей души» (ГончАРОв 1998: 5).

Возможно, в образе Обломова сказывается воздействие идей античного стоицизма, ставившего внутренний покой, внутреннюю волю превыше всего. Сенека в ряде трактатов писал о примате созерцания над действием, при этом действием оказывалось уже само созерцание (ГримАль 2003: 176).

Именно Штольц открывает глубину личности Обломова, но Штольц же пытается вывести протагониста на простор уже внешней деятельности: «без него Обломов опять ввергался весь по уши в свое одиночество и уединение» (ГОНчаров 1998: 59).

Обломов понимает, что внешняя активность повредила бы его внутреннему покою, нарушила бы «мягкость души». Как впоследствии будет говорить М. М. Бахтин: всякая активность всегда преступна. Обломов отнюдь не против внешних действий, не против исторического движения, жизненного роста, развития. Но «он бы желал, чтоб это сделалось как-нибудь так, незаметно, само собой» (ГончАРов 1998: 14). Важно напомнить в этой связи слова М. Элиаде о том, что «сопротивление всякому движению» - «первичное условие космогонии» (ЭлиАдЕ 2009: 92). «Незаметность» необходимой трансформации предполагает фокусировку и на «внутреннем» в человеке (смысловое преображение мира), и на некую «магию» космогонии, совершающейся «сама собой», по одному слову, как у Гоголя. В то же время сам Обломов понимает, что только одного этого недостаточно.

Отношения Обломова и Штольца являются символическим воплощением идеи необходимости синтеза русского «мягкого» «покоя» с западной предприимчивостью, «культурно-коммерческой деятельностью» (АннЕнский 1988a: 663). Но сами по себе состояния покоя и предприимчивости выступают у Гончарова - скорее всего, в русле диалектических построений Гегеля как «две реальные сущности, противоположных по содержанию, но способных к некоторому примиренно-творческому соотношению» (Ильин 1994: 141).

Синтез названных сторон - по Гегелю, «спекулятивная ассимиляция» состоит в том, что «каждая из сторон живым, творческим образом приемлет в себя все содержание другой стороны и целостно вживает его в своей собственное содержание. И обратно: каждая из сторон целостно отдает все свое содержание другой стороне, приемлется ею и вживается в ее, доселе самостоятельное содержание. Каждая переводит другую на свой язык, и сама переводится на ее язык» [здесь и далее выделено И. А. Ильиным] (Ильин 1994: 143).

При этом «спекулятивная ассимиляция заканчивается не гибелью сторон и не утратою их своеобразия, но только содержательным уподоблением» (Ильин 1994: 145). Обломов и Штольц, очерчивая два разных подхода к человеку и миру, являются друзьями. Они нуждаются друг в друге, их парность выражает некий социально-космический универсальный закон соотнесенности противоположностей и необходимости их синтеза.

И. Ф. Анненским отмечено, что Штольц является у Гончарова подобно богу из машины (Анненский 1988а: 655), т. е. в виде в высоком значении «ис- 
кусственного» приема. То же - «бог их машины» - можно сказать и о гоголевском Костанжогло, сходным путем представленного «инонациональным» типом. Однако если Штольц - наполовину немец, т. е. человек имеющий прямое отношение к Западу, то Костанжогло - грек, чем подчеркивается близость искомого Гоголем «мессии» восточному христианству.

Наиважнейший для Гончарова принцип парности персонажей, их противопоставления и одновременно соотнесения был задан еще в Обыкновенной истории через диаду «дядя /племянник». Но в первом произведении романной трилогии Гончарова идея синтеза противоположностей в основном отсутствовала, иногда проявляясь через идею их парадоксальной взаимозамены в финале. Поэтому для Обыкновенной истории актуален кантовский тип диалектики с его двумя составляющими без идеи их последующего синтеза. Но и в Обломове синтез как вид рецепции Гегеля все же только намечен - символическим в этой связи является тот факт, что Штольц и Ольга взяли сына умершего Обломова на воспитание.

Однако сам синтез в Обломове не осуществлен, хотя его заданность и, видимо, перенесенность в будущее очевидны и тайно вдохновляют всю объективную художественную идею романа - с элементами авторского субъективного скепсиса в отношении самой возможности для синтеза реально осуществиться. В Обрыве же, по сравнению с Обыкновенной историей и Обломовыл, принцип диады в качестве основного для группирования персонажей и художественной реальности произведения в целом отступает, мерцая лишь в частностях.

Толстой в своем художественном творчестве принципиально поднимает проблему «философии хозяйства» начиная с Анны Карениной (хотя можно вспомнить и Три смерти и Поликушку). Это связано с его будущим поворотом в сторону «опрощения» и крестьянского мессианизма. «Правильный» домовитый Левин противопоставлен Анне в качестве истинного примера семьянина и помещика. Следуя руссоистской утопии, Толстой пытается показать через левинское имение образец хозяйственной идиллии совместного труда помещика и крестьян. Конструирование подобной идиллии близко Гоголю. В поздний период толстовского творчества диада «помещик» / «крестьянин» перерастает в символическую пару «хозяина» и «работника», причем под членами пары будут подразумеваться Бог и человек (всякий человек).

Начиная с Записок сумасшедшего Толстой вводит в свое творчество мотив мнимо успешной хозяйственной сделки, приводящей к неожиданно негативному результату. Данный мотив есть также в Хозяине и работнике, Корнее Васильеве. Гонясь за законной выгодой и пытаясь реализовать логично вытекающие из хозяйственной практики задачи, герои приходят к некоей катастрофе, которая, однако, в конечном итоге оказывается «благотворной» (Е. М. Мелетинский) для развития их духа (но не материальных условий существования).

Герой толстовских Записок сумасшедщего после успешной сделки ощущает страх смерти и он испытывает острейший духовный кризис. Брехунов 
в буран отправляется за выгодной покупкой и замерзает. Корней Васильев после удачного гешефта пытается заработать еще, но возникающие перипетии приводят его к разрыву с семьей, к потере имущества, странничеству и смерти. В то же время кризис подводит героев к духовной трансформации, означающей отвержение земного успеха и выбор дела души.

Поздний Толстой всячески дискредитирует саму идею успешного хозяйства в качестве якобы залога истинного обретения себя. На первый план теперь выдвигается герой-одиночка, лишь служащий у богатого мужика и выполняющий нехитрую мужицкую работу «первобытного» типа, т. е. работу, какой она была до всякой «философии хозяйства» и до самого хозяйства вообще. Такими одиночками становятся Касатский (Отец Сергий; имеется в виду финал - работа на заимке у богатого мужика), батрак Никита (Хозяин и работник), Алеша Горшок из одноименного рассказа.

В позднем очерке Благодарная почва (Из дневника) Толстой прямо указывает на необходимость «единичной» (народ здесь осознан в качестве некоей «единичности») работы на земле в противоположность всем другим хозяйственным, техническим и иным цивилизационным ухищрениям:

Да, какая чудная земля не переставая парует, дожидаясь семени и зарастает сорными травами. Мы же, имеющие возможность отдать этому народу хоть чтонибудь из того, что мы не переставая берем от него, - что мы даем ему? Аэропланы, дредноуты, тридцатиэтажные дома, граммофоны, кинематографы и все те ненужные глупости, которые мы называем наукой и искусством. И главное пример пустой, безнравственной, преступной жизни. [...] А то вместо уплаты хоть части своего неоплатного долга перед ним мы засевам эту алчущую истинного знания землю одними «терниями и волчцами», запутываем этих милых, открытых на все доброе, чистых, как дети, людей коварными, умышленными обманами (Толстой 1936: 35).

Во второй половине XX века близкую Толстому (и Гоголю) мысль несколько другими словами и в несколько других категориях выразит М. Хайдеггер: «Если человек не подчинился ладу зова, исходящего от дороги, он напрасно тщится наладить порядок на земном шаре, планомерно рассчитывая его» (ХАЙдЕГгеР 1993: 240). Хайдеггер имеет в виду императив верности личности своему естественному (в значении, напоминающем Руссо) хронотопу («проселку»), верности, которая и позволяет ей состояться, пребыть. «Внутреннее» для Толстого, во многом Гоголя, отчасти Гончарова, позднее для Хайдеггера оказывается важнее «внешнего», на котором сфокусировался Булгаков.

\section{Литература}

АннЕНСКИй 1988a = АннЕнский И. Ф. Гончаров и его Обломов. В кн.: АнНЕнСКИй И. Ф. Избранные произведения. Ленинград, 1988. 641-669.

АнненСкий $1988 \mathrm{~b}=$ Анненский И. Ф. Эстетика «Мертвых душ» и ее наследье. В кн.: Анненский И. Ф. Избраннье произведения. Ленинград, 1988. 623-633. 
БЕРДяЕВ 1991 = БЕРДЯЕВ Н. А. Возрождение православия (о. С. Булгаков). В кН.: БЕРдяев Н. А. О русской философии. Ч. 2. Свердловск, 1991. 167-197.

БулгАКОВ 1993а = БулГАКОВ С. Н. Софийность хозяйства. В кн.: Русский космизм. Антология философской мысли. Москва, 1993. 131-140.

БулГАКОВ $1993 \mathrm{~b}=$ БулГАКОВ С. Н. Философия хозяйства. В кН.: БулГАКОВ С. Н. Сoчинения в 2 томах. Т. 1. Москва, 1993. 47-308.

Бэкон 1972 = Бэкон Ф. Новый Органон. В кн.: Бэкон Ф. Сочинения в 2 томах. Т. 2. Москва, 1972. 5-222.

ГетЕ $1976=$ ГЕТЕ И. В. Собрание сочинений в 10 томах. Т. 2. Москва, 1976.

Гоголь = ГоГоль Н. В. Полное собрание сочинений и писем в 17 томах. Москва-Киев, 2009-2010.

ГОЛЬДЕНБЕРГ 2012 = ГОЛЬДЕНБЕРГ А. Х. Аpхетипь в поэтике Н. В. Гоголя. Москва, 2012.

ГОНЧАРОВ $1998=$ ГОНЧАРОВ И. А. Полное собрание сочинений и писем в 20 томах. Т. 4. Санкт-Петербург, 1998.

ГримАЛЬ 2003 = ГРИМАЛЬ П. Сенека, или Совесть империи. Москва, 2003.

ЗЕнькОВСКий 1997 = ЗЕньковский В. В. Гоголь. Москва, 1997.

Ильин 1994 = Ильин И. А. Философия Гегеля как учение о конкретности Бога и человека. Санкт-Петербург, 1994.

МЕРЕЖКОВСКИЙ $1991=$ МЕРЕЖКОВСКИЙ Д. С. Гончаров. В кН.: МЕРЕЖКОВСКИЙ Д. С. Акрополь. Москва, 1991. 127-142.

Никитин $1989=$ Никитин В. А. Гоголь и Н. Ф. Федоров («Мертвые души» и «Живое слово»). Символ. № 21. Париж, 1989. 157-177.

Семенова-ГАчева 1993 = Семенова С. Г., ГАчева А. Г.: С. Н. Булгаков. В кн.: Русский космизм. Антология философской мыслли. Москва, 1993. 129-131.

Толстой 1936 = Толстой Л. Н. Полное собрание сочинений в 90 томах. Т. 38. Москва, 1936.

ХАЙДЕГГЕР 1993 = ХАЙДЕГГЕР М. Работы и размышиления разных лет. Москва, 1993.

ЭЛИАДЕ 2009 = ЭЛИАДЕ М. История веры и религиозных идей. От каменного века до элевсинских мистерий. Москва, 2009. 